\title{
Library publisher resources Making publishing approachable, sustainable, and values-driven
}

$\mathbf{T}$ he Library Publishing Coalition (LPC) defines library publishing as the "creation, dissemination, and curation of scholarly, creative, and/or educational works" by college and university libraries. ${ }^{1}$ While providing a publishing platform, hosting, and services for editorial teams is key to any library publishing initiative, library publishing is also centered on furthering core library values. Thus library publishing activities are mission-driven, centered on education, ${ }^{2}$ and focused on finding and promoting sustainable approaches to open access publishing and building cooperative open infrastructure. ${ }^{3}$

Micah Vandegrift and Josh Bolick capture this sentiment, stating that library publishers have a responsibility to "[act] as "library publishers' rather than 'publishing libraries,"' using publishing work to uphold and further our commitment to access and inclusion. ${ }^{4}$

Similarly, Charlotte Roh finds that library publishing activities have the potential to "[allow] new voices to find their way into disciplinary conversations, reach new audiences, . . . impact existing and emerging fields of scholarship and practice," and further larger library goals related to copyright and information literacy. ${ }^{5}$

Library publishing as a field continues to grow, in part because of its immediate, tangible benefits for each institution's constituents, as well as its ability to effect greater systematic change. LPC, a membership association of academic and research libraries and library consortia engaged in scholarly publishing, now has more than 80 members. ${ }^{6}$ The Association of University Presses' 2013 LibraryPress Collaboration Survey found that library publishing services are on the rise, with $65 \%$ of respondents saying that "library-publishing programs are an increasingly important service." In 2016, LPC and Educopia received an IMLS grant to train 60 librarians on publishing concepts, help ten libraries launch or enhance their publishing services, and integrate materials into at least one LIS course, signaling maturity in the field. ${ }^{8}$

As the number of institutions doing library publishing work grows, more library publishing resources and tools become available. Moreover, as library publishing becomes more accessible to different kinds of institutions, a greater diversity of resources is created. While some of these resources are intended to provide professional development for other library publishers, many more are designed to train potential and current editors and other stakeholders at the library publisher's own institution. There has been little accounting of these resources. LPC provides a shared documentation portal, but the space is still developing. ${ }^{9}$ Overall, library publishing resources

Jenny Hoops is digital publishing assistant, email: jhoops@iu.edu, and Sarah Hare is scholarly communication librarian, email: scrissin@iu.edu, at Indiana University-Bloomington

(C) 2019 Jenny Hoops and Sarah Hare 
are dispersed and can be time-consuming to locate.

\section{Library publishing resources}

This article highlights exemplary library publishing resources that are educational and prompt editorial team reflection about author rights, open access, or experimental publishing. We hope that this will serve as an immediately useful resource for those embedded in library publishing work, as many of these resources can be easily adapted and remixed. We also hope that this audit of current tools and resources will inspire the development and sharing of new resources that all library publishers can use.

We showcase three resources meant to facilitate journal creation and onboarding for new editors: Boston College Libraries' "Creating a New OJS Journal: Decisions" worksheet, ${ }^{10}$ the University of Toronto's "Journal Proposal Form"11 and our own Indiana University's "New Journal Toolkit." ${ }^{12}$ Instead of comparing resources to one another, we found it useful to evaluate resources on a few core tenants of library publishing: accessibility to new editors, a clear division of responsibilities between editors and library publishing staff, and promotion of library values.

\section{Broadening access}

Clear and dynamic library publishing resources broaden accessibility to publishing for new editors. Publishing, particularly in a digital medium and for academic purposes, comes with an array of exclusive jargon. Editorial teams might not understand the importance of DOIs and ISSNs for author evaluation and discoverability, and the prospect of having to craft a copyright policy might be intimidating. Resources that delineate the steps of publishing a journal can help editorial teams broach publishing generally and open access publishing specifically.

Boston College's "Creating a New Journal" worksheet guides editors through the most important features to consider when establishing an open access journal. The worksheet is shared under a CC-BY-NC-SA license, allowing other library publishers to adapt the tool to their context. The worksheet presents editorial decisions in checklist format, listing journal scope, content, policy, and requirements for indexing and preservation. These decisions are broken down in more detail, explaining potentially confusing or inaccessible editorial and technical terms.

Likewise, the University of Toronto's "Journal Proposal" sets new editors up for success. The form's section on sustainability asks editors to anticipate publishing costs as well as manager turnover, imploring editors to have a clear plan for documentation and knowledge transfer when editors move on. Publishing student journals is an integral way that library publishers broaden access to publishing, and this information is especially helpful for student editors, as turnover is a consistent challenge with editors continually graduating and leaving the institution.

Indiana University's "New Journal Toolkit" also guides new editors unfamiliar with publishing policies and processes. Built on Qualtrics, the toolkit is responsive to user input, skipping questions according to the unique needs of a journal based upon previous responses. In addition, the survey offers help text throughout for editors to explore or adapt. As an example, if an editor is unfamiliar with what a conflict of interest policy for reviewers might entail, the form links out to an example policy. These resources are more than policy documents, they guide users step by step, encouraging them to consider every part of the publishing process before launching a journal. They also assist the library publisher, as editors are more likely to ask for additional library assistance after developing a fully formed idea.

\section{Establishing responsibilities for sustainability}

Library publishing resources can also help establish divisions of responsibility be- 
tween the library publishing program and editorial teams, ensuring that editors feel supported in their publishing endeavors without requiring that library staff provide assistance during every part of the publishing workflow. Ensuring that editorial teams can work autonomously is paramount for library publishers, as programs are often serving several publications with limited staff and resources. Establishing roles and expectations while being upfront about capacity from the outset furthers the sustainability of publishing programs, most immediately by ensuring that library staff aren't overburdened.

For example, to complete Indiana University's "New Journal Toolkit," editors must check a box confirming that they have read through a detailed description of the various aspects of creating and maintaining an online journal. These responsibilities are split into three sections: work to be completed solely by the editorial team, such as the editorial workflow; tasks that fall to Indiana University Libraries staff, such as maintaining the OJS platform; and a list of collaborative duties.

By checking the boxes at the bottom of each section, editors are acknowledging that they have read through this division of labor and understand their responsibilities, as well as the support structures that will be provided by the hosting institution. Providing clear expectations helps foster a more collaborative relationship between editors and library staff, serving the publication while still setting boundaries that enable the publishing program to serve all journals.

Boston College's "Creating a New Journal" worksheet asks editors whether they plan to mint DOIs. An editor unfamiliar with digital publishing, particularly a student or new editor, could possibly be confused or alienated by this question that frequently appears. Boston College Libraries defines and emphasizes the necessity of DOIs, but also informs readers that the program will mint DOIs for individual articles and issues. Potential editors thus understand that DOIs are an important part of making their journal accessible and searchable, and that Boston College Libraries is ready to assist with minting them if they so choose.

Publishing can be difficult, time-consuming work for editors and publishers alike. To create truly cooperative services for editors, library publishers can establish clear divisions of labor during the onboarding process. Ensuring that various technical and editorial responsibilities are clearly delineated is an essential aspect of these publishing tools, which contributes to the general sustainability and longevity of library publishing programs.

\section{Furthering values}

Many new library publishing tools also integrate aspects of the university library's mission into the publishing process, including a commitment to open access and furthering nontraditional scholarship. This ensures that the institution's values will be promoted while providing editors a uniform set of rules and policies by which to regulate their publication.

The University of Toronto's "Journal Proposal" worksheet has a section titled "Market Analysis," which helps new editors interrogate the aim and scope of their journal in realistic, reader-driven ways. This resource requires an editor to list competing journals in the field, and then explain how the journal they hope to establish will create meaningful scholarship that is unique and engaging. While library publishing provides opportunity for a variety of potential editors with no other accessible platform, questions such as these ensure that editors are creating impactful journals.

As editors work their way through Indiana University's "New Journal Toolkit," they are provided with example policies and guidelines from open access journals. While editors have the agency to craft their journal's policy, the copyright samples prioritize author rights, encouraging them to apply a similar policy that aligns with Indiana University's open publishing goals. 
A notes section listed near each decision on Boston College's worksheet provides specific methods or language Boston College Libraries provides for new journals, such as LOCKSS membership and an open access statement. Several of the worksheet's decisions are "pre-checked," enabling editors to understand what services Boston College Libraries will provide while still receiving a full list of the necessary steps for establishing a journal. Since an open access policy is provided, journals are encouraged to make their content openly available.

Library publishing programs must find a balance between maintaining editorial team agency and giving their editors creative freedom while maintaining the values of the sponsoring library. These tools showcase ways in which editors are encouraged to embrace values of openness, author rights, and quality scholarship without overly restricting each journal.

\section{Conclusion}

As library publishing continues to flourish, it is imperative that our resources provide potential editors with the knowledge needed to produce new content. Creating resources that clarify the role of the library publisher, educate users on integral concepts like Creative Commons and DOIs, and further the library's commitment to access and preservation is important work.

Sharing these resources with each other, as a community of practice, is just as important. The library publishing community continually emphasizes a commitment to cooperative, community-driven work. One way we further this commitment is by sharing our own resources, both polished and unpolished, with others, preferably licensed in a way that empowers others to adapt and revise them. Sharing also makes library publishing visible to those with a stake in publishing literacy broadly, including repository managers, copyright officers, and information literacy librarians. Most importantly, sharing will empower us to build upon one another's work and serve our editors and institutions more effectively.

\section{Notes}

1. Educopia Institute, "What is Library Publishing?" Library Publishing Coalition, accessed November 2, 2018, https:// librarypublishing.org/.

2. Charlotte Roh, "Library publishing and diversity values," College \& Research Libraries News 77(2) (2016): 82-85, https:// crln.acrl.org/index.php/crlnews/article /view/9446/10680.

3. D. Russell Bailey, "Creating digital knowledge: Library as open access digital publisher," College \& Undergraduate Libraries 24(2-4) (2017): 220-25, doi: 10.1080/10691316.2017.1323695.

4. Micah Vandegrift and Josh Bolick, "Free to All": Library Publishing and the Challenge of Open Access," Journal of Librarianship and Scholarly Communication, 2(4), (2014), 107, doi: 10.7710/21623309.1181.

5. Roh, "Library publishing and diversity values," 83-84.

6. "What is Library Publishing?" Library Publishing Coalition, https://librarypublishing. org/.

7. AAUP Library Relations Committee, "Press and Library Collaboration Survey," (2013), accessed November 4, 2018.

8. "RE-40-16-0150-16: Educopia Institute," Institute of Museum and Library Services, https://www.imls.gov/grants/awarded /re-40-16-0150-16.

9. "Shared Documentation," Library Publishing Coalition, accessed November 9, 2018, https://librarypublishing.org/category /resources/documentation/.

10. "Creating a New OJS Journal: Decisions," Boston College Libraries, accessed October 15, 2018, https://libguides.bc.edu /c.php?g=395518\&p=4961569.

11. "Journal Proposal Form," University of Toronto Libraries, accessed October 28, 2018, https://jps.library.utoronto.ca/index. php/pubguide/starting.

12. "New Journal Toolkit," Indiana University Libraries, accessed October 22, 2018, https://wiki.dlib.indiana.edu/display/IUSW /OJS+3+Instructions+for+Editors. n 